\title{
ANÁLISE DOS RESULTADOS BIÓTICOS E ABIÓTICOS DA RESTAURAÇÃO DA MATA CILIAR DE NASCENTE UTILIZANDO TÉCNICAS DE NUCLEAÇÃO
}

\author{
Carla Tiemi Fukumoto; Renata Ribeiro de Araújo.
}

Engenharia Ambiental. Departamento de Planejamento, Urbanismo e Ambiente. UNESP - Presidente Prudente. Email: carlatiemi@hotmail.com. FAPESP - Fundação de Amparo à Pesquisa do Estado de São Paulo.

\section{RESUMO}

O presente estudo apresenta os resultados do monitoramento das técnicas de nucleação implantadas a fim de recuperar a mata ciliar de uma nascente do Ribeirão Laranja Doce no município de Nantes-SP. As técnicas monitoradas são: transposição de galharia, transposição de solo e serrapilheira, poleiros naturais e artificiais e os Núcleos de Anderson. 0 método utilizado baseia-se no protocolo de monitoramento apresentado pela Secretaria do Meio Ambiente do Estado de São Paulo, no Caderno da Mata Ciliar, no 4, 2011. Foram realizados dois monitoramentos mensais. Os resultados foram satisfatórios para as técnicas, mas a maior dificuldade encontrada foi a presença do gado bovino na área, mesmo com o cercamento e a falta de manutenção. Podendo-se concluir que o monitoramento é importante para acompanhar a evolução e as dificuldades do processo.

Palavras-chave: técnicas de nucleação; restauração; mata ciliar; monitoramento; nascente.

\section{INTRODUÇÃO}

O crescimento da população brasileira e sua ocupação territorial sem planejamento foram fatores que contribuíram para a degradação dos recursos naturais, particularmente das florestas (MARTINS, 2007). Segundo Brannstrom e Oliveira (2000), o processo de ocupação do Oeste Paulista não foi diferente, ele teve como consequência uma grande degradação ambiental, devido à retirada da vegetação primitiva para a expansão agropecuária, além de inadequado uso do solo e crescimento urbano desorganizado.

Segundo Engel \& Parrotta (2008), quando a degradação ambiental atinge um estágio muito avançado, o ecossistema perde a capacidade de regeneração natural das espécies, sendo necessária a intervenção humana, a fim de estabilizar e reverter os processos de degradação, acelerando e direcionando a sucessão natural.

Tradicionalmente, a recuperação dessas áreas degradadas, baseia-se num contexto fortemente dendrológico, primando pela introdução de espécies arbóreas, muitas delas exóticas e plantios em linhas, uniformizando a área a ser recuperada. Esses métodos são caros, podem propiciar a contaminação biológica local e não solucionam completamente o problema (REIS et al., 2004). 
Por outro lado, a restauração ambiental possui como objetivo, chegar o mais próximo possível de sua condição original, trazendo novamente todas, ou a maior parte das espécies e interações entre elas, almejando alcançar níveis de sucessão que atinjam a estabilidade e integridade ecológica dos ecossistemas naturais (REIS \& KAGEYAMA, 2008).

A restauração por meio da técnica de nucleação enquadra-se neste conceito de restauração buscando restabelecer as interações ecológicas naturais do ecossistema, uma vez que os núcleos de vegetação da área degradada alteram as condições ambientais, favorecendo a expansão da vegetação secundária, dando continuidade ao processo de sucessão dessa área (REIS et al., 2003).

O método envolve a implantação de várias técnicas nucleadoras, as quais geram consequências particulares para o ambiente. Se implantadas em conjunto, elas possibilitam o resgate do fluxo natural no sistema degradado. Visando melhores resultados, as técnicas nucleadoras devem ocupar uma parcela pequena da área em questão, no máximo 5\% da mesma, enquanto que o restante da área sofre influência dos núcleos e encontra-se vulnerável as alterações da sucessão secundária, ou seja, a maior extensão é destinada a regeneração natural.

Neste contexto, a fim de recuperar a mata ciliar de uma nascente, técnicas de nucleação (transposição de solo e serrapilheira, transposição de galharia, poleiros naturais e artificiais e núcleos de Anderson), foram implantadas.

A área de estudo compreendeu uma nascente degradada de uma propriedade rural localizada na Fazenda São Pedro, no Ribeirão Laranja Doce, município de Nantes-SP, latitude $22^{\circ}$ $31^{\prime} 39^{\prime \prime}$ O e longitude $51^{\circ} 16^{\prime} 01^{\prime \prime}$ S. O Ribeirão Laranja Doce pertence à Bacia Hidrográfica da Represa Laranja Doce, que faz parte da Unidade de Gerenciamento de Recursos Hídricos 22 Pontal do Paranapanema e é gerida pelo Comitê desta UGRHI.

A área restaurada foi calculada de acordo com o disposto na Lei Federal no 12.651, de 25 de maio de 2012, que prevê a área de preservação permanente para as áreas no entorno de nascentes.

Inicialmente foi realizada a caracterização da área, assim como os levantamentos florístico e faunístico do local. Através dos dados obtidos, confirmou-se a potencialidade para a restauração da mata ciliar utilizando as técnicas de nucleação.

Para a aplicação das técnicas a área foi preparada pelo proprietário das terras, sendo: i) demarcação do terreno, ii) cercamento da área, para isolar dos agentes degradadores, iii) roçada mecânica em área total e iv) abertura de coroas. Então, foi realizada a confeç̧ão de v) sete 
transposições de galharia, vi) oito transposições de solo e serrapilheira, vii) 6 poleiros naturais e artificiais e viii) doze núcleos de Anderson.

Para verificação da direção sucessional o monitoramento da área é fundamental. Neste sentido, o presente estudo apresenta os resultados do monitoramento realizado na área em que foram implantadas as técnicas de nucleação.

\section{OBJETIVO GERAL}

Analisar os resultados bióticos e abióticos da restauração ambiental de uma nascente do ribeirão Laranja Doce no município de Nantes/SP.

\section{OBJETIVOS ESPECÍFICOS}

Avaliar a presença de degradantes bióticos e abióticos;

Quantificar e qualificar os regenerantes nos diferentes núcleos, além de avaliar indicadores específicos de cada núcleo.

\section{MÉTODOS}

O monitoramento das técnicas de nucleação, implantadas para recuperação da mata ciliar de uma nascente do Ribeirão Laranja Doce no município de Nantes-SP, ocorreu através de duas visitas a campo, com intervalo de um mês entre as visitas.

O monitoramento foi baseado no protocolo recomendado pela Secretaria do Meio Ambiente do Estado de São Paulo (2011).

Os indicadores avaliados no monitoramento foram divididos quanto a: estrutura e composição (Quadro 1). O grupo composição foi dividido conforme a técnica nucleadora utilizada. 
Encontro de Ensino, Pesquisa e Extensão, Presidente Prudente, 21 a 24 de outubro, 2013

Quadro 1. Indicadores quanto à estrutura e composição.

\begin{tabular}{|c|c|}
\hline & Estrutura \\
\hline a. & Fatores degradantes bióticos: \\
\hline \multicolumn{2}{|r|}{ Pastoreio: observação direta da presença e de sinais do gado bovino; } \\
\hline \multicolumn{2}{|r|}{$\begin{array}{l}\text { Plantas invasoras: aferição da cobertura de plantas invasoras nos núcleos pelo método de } \\
\text { Fournier (dividido em quatro categorias: 0-25/26-50/51-75/76-100); }\end{array}$} \\
\hline \multicolumn{2}{|r|}{ Excesso de formigas cortadeiras: a contagem de olheiros; } \\
\hline b. & Fatores degradantes abióticos: \\
\hline \multicolumn{2}{|r|}{$\begin{array}{l}\text { Fogo: observação direta de sinais de fogo e porcentagem da área atingida, pelo método de } \\
\text { Fournier; }\end{array}$} \\
\hline \multicolumn{2}{|r|}{ Processos erosivos: a observação direta da ocorrência de erosão laminar, sulcos e voçorocas; } \\
\hline & 2. Composição \\
\hline \multicolumn{2}{|c|}{ Transposição de galharia } \\
\hline \multicolumn{2}{|r|}{$\begin{array}{l}\text { a. Indícios de ocorrência de fauna: presença ou ausência de sinais, como } \\
\text { tocas/esconderijos/ninhos, fungos, insetos, aracnídeos, anfíbios e outros; }\end{array}$} \\
\hline \multicolumn{2}{|r|}{ Transposição de solo } \\
\hline \multicolumn{2}{|r|}{ Ocorrência de germinação: ausência ou presença de germinação no solo transportado } \\
\hline \multicolumn{2}{|r|}{ Poleiros naturais e artificiais } \\
\hline & Ocorrência de avifauna: verificação de presença/ausência de aves; \\
\hline & Sinais: observação da presença/ausência de fezes, pegadas e sementes; \\
\hline & Germinação: quantificação das espécies vegetais emergentes sob o poleiro. \\
\hline \multicolumn{2}{|r|}{ Núcleos de Anderson } \\
\hline & Sobrevivência: quantificação das mudas sobreviventes. \\
\hline
\end{tabular}

\section{RESULTADOS}

As localizações espaciais dos núcleos implantados encontram-se na Figura 1.

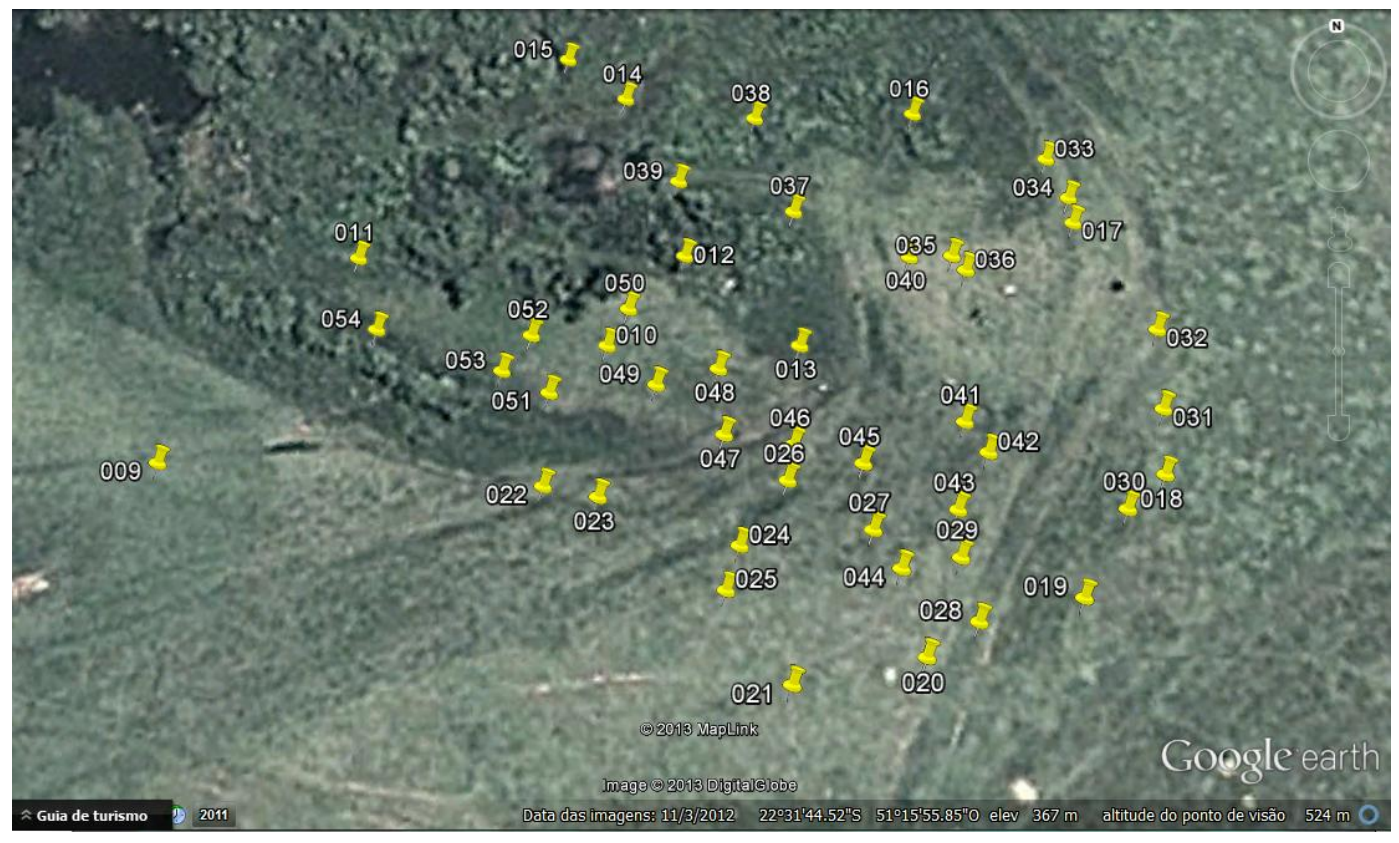

Figura 1. Localização espacial dos núcleos (Fonte: Google earth). 
Os resultados obtidos durante o monitoramento quanto a técnica de transposição de galharia estão apresentados nos Quadros 2 e 3.

Quadro 2. Transposição de Galharia (1ำ mês)

\begin{tabular}{|c|c|c|c|c|c|c|}
\hline \multirow{2}{*}{$\begin{array}{c}\text { Núcle } \\
0\end{array}$} & \multicolumn{4}{|c|}{ Estrutura } & Composição \\
\cline { 2 - 7 } & Fatores degradantes bióticos & \multicolumn{2}{|c|}{$\begin{array}{c}\text { Fatores degradantes } \\
\text { abióticos }\end{array}$} & Galharia \\
\cline { 2 - 7 } & Pastoreio & $\begin{array}{c}\text { Invasora } \\
\text { s }\end{array}$ & Formigas & Fogo & Proc. erosivos & Fauna \\
\hline 023 & Ausência & $26-50$ & 0 & Ausência & Ausência & $\begin{array}{c}\text { Fezes de aves, insetos, } \\
\text { fungos }\end{array}$ \\
\hline 026 & Ausência & $0-25$ & 6 & Ausência & Ausência & $\begin{array}{c}\text { Fezes de aves, insetos, } \\
\text { fungos. }\end{array}$ \\
\hline 029 & Ausência & $0-25$ & 0 & Ausência & Ausência & Fungos, insetos. \\
\hline 040 & Ausência & $0-25$ & 5 & Ausência & Ausência & $\begin{array}{c}\text { Esconderijo, fezes de } \\
\text { aves, insetos, fungos. }\end{array}$ \\
\hline 042 & Ausência & $26-50$ & 0 & Ausência & Ausência & Insetos, fungos. \\
\hline 045 & Ausência & $76-100$ & 0 & Ausência & Ausência & Insetos, fungos. \\
\hline 053 & Presença & $76-100$ & 0 & Ausência & Ausência & $\begin{array}{c}\text { Esconderijo, fezes de } \\
\text { aves, insetos, fungos. }\end{array}$ \\
\hline
\end{tabular}

Quadro 3. Transposição de Galharia (2ํ mês)

\begin{tabular}{|c|c|c|c|c|c|c|}
\hline \multirow{3}{*}{$\begin{array}{c}\text { Núcle } \\
\text { o }\end{array}$} & \multicolumn{5}{|c|}{ Estrutura } & Composição \\
\hline & \multicolumn{3}{|c|}{ Fatores degradantes bióticos } & \multicolumn{2}{|c|}{$\begin{array}{c}\text { Fatores degradantes } \\
\text { abióticos }\end{array}$} & Galharia \\
\hline & Pastoreio & $\begin{array}{c}\text { Invasora } \\
\mathrm{s}\end{array}$ & Formigas & Fogo & Proc. erosivos & Fauna \\
\hline 023 & Ausência & $26-50$ & 0 & Ausência & Ausência & $\begin{array}{c}\text { Fezes de aves, insetos, } \\
\text { fungos }\end{array}$ \\
\hline 026 & Ausência & $0-25$ & 1 & Ausência & Ausência & $\begin{array}{c}\text { Fezes de aves, insetos, } \\
\text { fungos. }\end{array}$ \\
\hline 029 & Presença & $26-50$ & 2 & Ausência & Ausência & Fungos, insetos. \\
\hline 040 & Presença & $76-100$ & 0 & Ausência & Ausência & $\begin{array}{l}\text { Esconderijo, fezes de } \\
\text { aves, insetos, fungos. }\end{array}$ \\
\hline 042 & Ausência & $26-50$ & 0 & Ausência & Ausência & $\begin{array}{c}\text { Fezes de aves, insetos, } \\
\text { fungos. }\end{array}$ \\
\hline 045 & Ausência & $0-25$ & 0 & Ausência & Ausência & $\begin{array}{c}\text { Fezes de aves, insetos, } \\
\text { fungos. }\end{array}$ \\
\hline 053 & Presença & $76-100$ & 0 & Ausência & Ausência & Fezes de aves, fungos. \\
\hline
\end{tabular}

Os resultados obtidos durante o monitoramento quanto a técnica de transposição de solo estão apresentados no Quadros 4 e 5. 
Encontro de Ensino, Pesquisa e Extensão, Presidente Prudente, 21 a 24 de outubro, 2013

Quadro 4. Transposição de Solo (1ำ mês)

\begin{tabular}{|c|c|c|c|c|c|c|}
\hline \multirow{2}{*}{$\begin{array}{c}\text { Núcle } \\
0\end{array}$} & \multicolumn{5}{|c|}{ Estrutura } & Composição \\
\cline { 2 - 6 } & Fatores degradantes bióticos & \multicolumn{2}{|c|}{$\begin{array}{c}\text { Fatores degradantes } \\
\text { abióticos }\end{array}$} & Transposição de Solo \\
\cline { 2 - 6 } & Pastoreio & $\begin{array}{c}\text { Invasora } \\
\text { s }\end{array}$ & Formigas & Fogo & Proc. erosivos & Germinação \\
\hline 025 & Ausência & $0-25$ & 0 & Ausência & Ausência & Ausência \\
\hline 027 & Ausência & $26-50$ & 0 & Ausência & Ausência & Ausência \\
\hline 028 & Ausência & $26-50$ & 0 & Ausência & Ausência & Ausência \\
\hline 031 & Presença & $0-25$ & 15 & Ausência & Ausência & Ausência \\
\hline 033 & Presença & $0-25$ & 6 & Ausência & Ausência & Ausência \\
\hline 038 & Ausência & $0-25$ & 4 & Ausência & Ausência & Presente \\
\hline 049 & Ausência & $0-25$ & 6 & Ausência & Ausência & Ausência \\
\hline 052 & Presença & $0-25$ & 4 & Ausência & Ausência & Ausência \\
\hline
\end{tabular}

Quadro 5. Transposição de Solo (2o mês)

\begin{tabular}{|c|c|c|c|c|c|c|}
\hline \multirow{2}{*}{$\begin{array}{c}\text { Núcle } \\
0\end{array}$} & \multicolumn{5}{|c|}{ Estrutura } & Composição \\
\cline { 2 - 7 } & Fatores degradantes bióticos & \multicolumn{2}{|c|}{$\begin{array}{c}\text { Fatores degradantes } \\
\text { abióticos }\end{array}$} & Solo \\
\cline { 2 - 7 } & Pastoreio & $\begin{array}{c}\text { Invasora } \\
\text { s }\end{array}$ & Formigas & Fogo & Proc. erosivos & Germinação \\
\hline 025 & Presença & $0-25$ & 1 & Ausência & Ausência & Ausência \\
\hline 027 & Ausência & $26-50$ & 0 & Ausência & Ausência & Presença \\
\hline 028 & Presença & $26-50$ & 0 & Ausência & Ausência & Ausência \\
\hline 031 & Presença & $26-50$ & 12 & Ausência & Ausência & Ausência \\
\hline 033 & Presença & $0-25$ & 2 & Ausência & Ausência & Ausência \\
\hline 038 & Ausência & $26-50$ & 3 & Ausência & Ausência & Presença \\
\hline 049 & Presença & $51-75$ & 1 & Ausência & Ausência & Ausência \\
\hline 052 & Presença & $0-25$ & 0 & Ausência & Ausência & Ausência \\
\hline
\end{tabular}

Os resultados obtidos durante o monitoramento quanto a técnica de poleiros naturais e artificiais estão apresentados no Quadros 6 e 7.

Quadro 6. Poleiros naturais e artificiais (10 mês)

\begin{tabular}{|c|c|c|c|c|c|c|c|c|}
\hline \multirow{3}{*}{$\begin{array}{c}\text { Núcle } \\
\text { o }\end{array}$} & \multicolumn{5}{|c|}{ Estrutura } & \multirow{2}{*}{\multicolumn{3}{|c|}{$\begin{array}{c}\text { Composição } \\
\text { Poleiros naturais e artificiais }\end{array}$}} \\
\hline & \multicolumn{3}{|c|}{$\begin{array}{c}\text { Fatores degradantes } \\
\text { bióticos }\end{array}$} & \multicolumn{2}{|c|}{$\begin{array}{c}\text { Fat. degradantes } \\
\text { abióticos }\end{array}$} & & & \\
\hline & $\begin{array}{l}\text { Pastorei } \\
\text { o }\end{array}$ & Invas. & Formig. & Fogo & P. erosivos & Avifauna & Sinais & $\begin{array}{c}\text { Germinaçã } \\
0\end{array}$ \\
\hline 030 & Ausência & $0-25$ & 0 & Ausência & Ausência & Presença & Presença & Ausência \\
\hline 036 & Presença & $26-50$ & 1 & Ausência & Ausência & Ausência & Presença & Ausência \\
\hline 039 & Ausência & $0-25$ & 0 & Ausência & Ausência & Presença & Presença & Ausência \\
\hline 043 & Ausência & $26-50$ & 0 & Ausência & Ausência & Ausência & Presença & Ausência \\
\hline 051 & Ausência & $26-50$ & 7 & Ausência & Ausência & Ausência & Presença & Ausência \\
\hline
\end{tabular}

Colloquium Exactarum, vol. 5, n. Especial, Jul-Dez, 2013, p. 164-172. ISSN: 2178-8332. DOI: 10.5747/ce.2013.v05.nesp.000067 
Encontro de Ensino, Pesquisa e Extensão, Presidente Prudente, 21 a 24 de outubro, 2013

Quadro 7. Poleiros naturais e artificiais (2을

\begin{tabular}{|c|c|c|c|c|c|c|c|c|}
\hline \multirow{3}{*}{$\begin{array}{l}\text { Núcle } \\
\text { o }\end{array}$} & \multicolumn{5}{|c|}{ Estrutura } & \multirow{2}{*}{\multicolumn{3}{|c|}{$\begin{array}{c}\text { Composição } \\
\text { Poleiros naturais e artificiais }\end{array}$}} \\
\hline & \multicolumn{3}{|c|}{$\begin{array}{c}\text { Fatores degradantes } \\
\text { bióticos }\end{array}$} & \multicolumn{2}{|c|}{$\begin{array}{c}\text { Fat. degradantes } \\
\text { abióticos }\end{array}$} & & & \\
\hline & $\begin{array}{c}\text { Pastorei } \\
0\end{array}$ & Invas. & Formig. & Fogo & P. erosivos & Avifauna & Sinais & $\begin{array}{c}\text { Germinaçã } \\
0\end{array}$ \\
\hline 030 & Ausência & $0-25$ & 0 & Ausência & Ausência & Ausência & Presença & Ausência \\
\hline 036 & Presente & $\begin{array}{l}76- \\
100\end{array}$ & 2 & Ausência & Ausência & Ausência & Presença & Ausência \\
\hline 039 & Ausência & $0-25$ & 0 & Ausência & Ausência & Ausência & Presença & Ausência \\
\hline 043 & Ausência & $26-50$ & 0 & Ausência & Ausência & Ausência & Presença & Ausência \\
\hline 051 & Presença & $51-75$ & 0 & Ausência & Ausência & Ausência & Presença & Ausência \\
\hline
\end{tabular}

Os resultados obtidos durante o monitoramento quanto a técnica de núcleo de Anderson estão apresentados no Quadros 8 e 9.

Quadro 8. Núcleos de Anderson (1ํmês)

\begin{tabular}{|c|c|c|c|c|c|c|}
\hline \multirow{3}{*}{$\begin{array}{c}\text { Núcle } \\
0\end{array}$} & \multicolumn{5}{|c|}{ Estrutura } & \multirow{3}{*}{$\begin{array}{c}\text { Composição } \\
\text { Núcleos de } \\
\text { Anderson } \\
\text { Sobrevivência }\end{array}$} \\
\hline & \multicolumn{3}{|c|}{ Fatores degradantes bióticos } & \multicolumn{2}{|c|}{ Fatores degradantes abióticos } & \\
\hline & Pastoreio & $\begin{array}{c}\text { Invasora } \\
\mathrm{s}\end{array}$ & Formigas & Fogo & $\begin{array}{l}\text { Processos } \\
\text { erosivos }\end{array}$ & \\
\hline 022 & Ausência & $26-50$ & 6 & Ausência & Ausência & 4 \\
\hline 024 & Ausência & $76-100$ & 4 & Ausência & Ausência & 0 \\
\hline 032 & Presença & $26-50$ & 25 & Ausência & Ausência & 4 \\
\hline 034 & Presença & $26-50$ & 7 & Ausência & Ausência & 4 \\
\hline 035 & Ausência & $0-25$ & 4 & Ausência & Ausência & 5 \\
\hline 037 & Ausência & $26-50$ & 4 & Ausência & Ausência & 4 \\
\hline 041 & Presença & $51-75$ & 4 & Ausência & Ausência & 3 \\
\hline 046 & Presença & $26-50$ & 5 & Ausência & Ausência & 1 \\
\hline 047 & Ausência & $51-75$ & 4 & Ausência & Ausência & 5 \\
\hline 048 & Presença & $0-25$ & 5 & Ausência & Ausência & 4 \\
\hline 050 & Ausência & $76-100$ & 4 & Ausência & Ausência & 3 \\
\hline 54 & Presença & $76-100$ & 0 & Ausência & Ausência & 4 \\
\hline
\end{tabular}


Quadro 9. Núcleos de Anderson (2ㅇês)

\begin{tabular}{|c|c|c|c|c|c|c|}
\hline \multirow{2}{*}{$\begin{array}{c}\text { Núcle } \\
\text { o }\end{array}$} & \multicolumn{5}{|c|}{ Estrutura } & Composição \\
\cline { 2 - 7 } & Fatores degradantes bióticos & \multicolumn{2}{|c|}{ Fatores degradantes abióticos } & $\begin{array}{c}\text { Núcleos de } \\
\text { Anderson }\end{array}$ \\
\cline { 2 - 7 } & Pastoreio & $\begin{array}{c}\text { Invasora } \\
\text { s }\end{array}$ & Formigas & Fogo & $\begin{array}{c}\text { Processos } \\
\text { erosivos }\end{array}$ & Sobrevivência \\
\hline 022 & Presença & $26-50$ & 4 & Ausência & Ausência & 4 \\
\hline 024 & Ausência & $76-100$ & 0 & Ausência & Ausência & 1 \\
\hline 032 & Ausência & $26-50$ & 8 & Ausência & Ausência & 4 \\
\hline 034 & Presença & $76-100$ & 5 & Ausência & Ausência & 5 \\
\hline 035 & Ausência & $26-50$ & 4 & Ausência & Ausência & 4 \\
\hline 037 & Presença & $26-50$ & 3 & Ausência & Ausência & 5 \\
\hline 041 & Ausência & $76-100$ & 4 & Ausência & Ausência & 3 \\
\hline 046 & Ausência & $51-75$ & 3 & Ausência & Ausência & 3 \\
\hline 047 & Ausência & $51-75$ & 2 & Ausência & Ausência & 4 \\
\hline 048 & Ausência & $26-50$ & 1 & Ausência & Ausência & 5 \\
\hline 050 & Presença & $76-100$ & 0 & Ausência & Ausência & 3 \\
\hline 54 & Ausência & $76-100$ & 0 & Ausência & Ausência & 4 \\
\hline
\end{tabular}

\section{DISCUSSÃO}

O monitoramento dos fatores degradantes bióticos na área onde foram implantadas as técnicas de nucleação indicou a presença de pastoreio, através da observação direta da presença de fezes e pegadas do gado bovino. Apesar do cercamento da área com o propósito de isolar a área do gado que era o principal agente degradador, o animal ainda teve acesso ao local prejudicando o processo de estabelecimento das técnicas.

Em relação à cobertura de plantas invasoras, pode-se observar que ela está avançando rapidamente devido principalmente à falta de manutenção da área, que seria a roçada manual seletiva do local. A contagem de olheiros de formigas apresentou um baixou número e observouse também que não ocorreu nenhum problema com as mudas plantadas decorrentes de formigas cortadeiras. Por outro lado, não foi encontrado indícios da presença dos fatores degradantes abióticos fogo e processos erosivos.

A composição de cada tipo de técnica de nucleação apresentou resultados satisfatórios, com indícios que a maioria núcleos está cumprindo sua função ecológica. Todos os núcleos de transposição de galharia apresentaram pelo menos a presença de dois sinais de ocorrência de fauna como esconderijos, fungos, insetos e fezes de aves.

$\mathrm{Na}$ transposição de solo e serrapilheira, foi observada a ocorrência de germinação em apenas dois núcleos, e esses dois núcleos foram os únicos que não tiveram a presença de sinais de gado, podendo então relacionar a não germinação nos núcleos devido ao pisoteio do gado. 
Os poleiros naturais e artificiais apresentaram a presença de fezes de aves, mas não foi possível fazer a identificação das espécies e ainda não há a ocorrência de germinação.

Por último, os Núcleos de Anderson tiveram mudas pisoteadas e arrancadas pelo gado, outras foram desenterradas por tatu, ocorrendo a morte de muitas delas, inclusive constatou a morte de todas as cinco mudas de um núcleo, tendo que ser realizado o replantio.

\section{CONCLUSÃO}

Com base nos resultados apresentados, é preciso que o monitoramento da área continue a ser realizado, para que se possam obter dados para a análise do processo de restauração da área. O monitoramento é importante para se identificar a evolução e as dificuldades que estão ocorrendo, e que podem diminuir as chances de sucesso do estabelecimento da sucessão ecológica da área degradada.

\section{REFERÊNCIAS}

BRANNSTROM, C. \& OLIVEIRA, A. M. S. Human modification of stream valleys in the western plateau of São Paulo, Brazil: implications for environmental narratives and management. Land Degradation \& Development, v. 11, 2000.

BRASIL. Lei n. 9.985, de 18 de julho de 2000. Diário Oficial da República Federativa do Brasil, Brasília, 9 setembro 2000. Disponível em: <http://www.planalto.gov.br/ccivil_03/Leis/L9985.htm>. Acesso em: 9 abril 2011.

ENGEL, V. L.; PARROTTA, J. A. Definindo a restauração ecológica: tendências e perspectivas mundiais. In: KAGEYAMA, P. Y.; OLIVEIRA, R.E; MORAES, L.F.D; ENGEL, V.L; GANDARA, F.B. Restauração ecológica de ecossistemas naturais. 1. ed. Botucatu-SP: FEPAF, 2008.

MARTINS, S. V. Recuperação de Matas Ciliares. 2. Ed. rev. e ampl. Viçosa, MG: Aprenda Fácil, p. $255,2007$.

REIS, A. et al. Restauração de áreas degradadas : a nucleação como base para incrementar os processos sucessionais. Natureza e conservação, Brasil, v.1, n.1, p 28-36, abril 2003.

REIS, A.; KAGEYAMA P. Y. Restauração de áreas degradadas utilizando interações interespecíficas. In: Restauração ecológica de ecossistemas naturais. 1ạ ed. Botucatu-SP: FEPAF, 2008.

SECRETARIA DO MEIO AMBIENTE (São Paulo). Monitoramento de áreas em recuperação. Cadernos da Mata Ciliar. São Paulo, no4, p. 27-31, 2011. 